\title{
Level V Evidence
}

\section{Rehabilitation and Return to Sport Following Elbow Injuries}

\author{
Kenneth M. Lin, M.D., Todd S. Ellenbecker, D.P.T., M.S., S.C.S., O.C.S., C.S.C.S., and \\ Marc R. Safran, M.D.
}

\begin{abstract}
Elbow injuries are frequently seen in throwing and overhead athletes. This review provides a framework for diagnosis, treatment, and particularly rehabilitation of common elbow pathologies, including ulnar collateral ligament injury, valgus extension overload, and medial and lateral epicondylitis. Advanced rehabilitation facilitates complete return to functional sport-specific activity and is based on objective criteria. As diagnostic and therapeutic modalities improve our understanding of elbow pathologies in the athletic patient, continued research will further elucidate objective evidencebased rehabilitation techniques.
\end{abstract}

$\mathbf{P}$ articipation and early specialization in throwing and overhead sports such as baseball, tennis, football, javelin, and volleyball have led to a rising prevalence of elbow injuries in an increasingly younger population. ${ }^{1}$ Throwing and other athletic overhead motions can produce supraphysiological loads across the elbow, which can predispose to injury. Furthermore, repetitive overhead motion without adequate rest or rehabilitation may result in chronic pathology. Elbow injuries can cause significant disability during athletic activity in specialized sports such as baseball ${ }^{2}$ and may also affect activities of daily living. Common injuries of the overhead or throwing elbow can be divided on the basis of anatomic location (medial, lateral, posterior, or anterior) or by chronicity, with most being chronic or acute on chronic. This review will focus on the diagnosis, treatment, and particularly rehabilitation of common elbow pathologies in overhead and throwing athletes, specifically ulnar collateral

From the Stanford University Department of Orthopaedic Surgery, Sports Medicine Service (K.M.L., M.R.S.), Palo Alto, California; and Rehab Plus Sports Therapy (T.E.), Scottsdale, Arizona, United States.

The authors report that they have no conflicts of interest in the authorship and publication of this article. Full ICMJE author disclosure forms are available for this article online, as supplementary material.

Received December 26, 2021; accepted January 27, 2022.

Address correspondence to Kenneth M. Lin, M.D., 450 Broadway, MC 6342, Redwood City, CA 94063,U.S.A.E-mail:kenmlin@stanford.edu

(C) 2022 THE AUTHORS. Published by Elsevier Inc. on behalf of the Arthroscopy Association of North America. This is an open access article under the CC BY-NC-ND license (http://creativecommons.org/licenses/by-nc-nd/4.0/). 2666-061X/211844

https://doi.org/10.1016/j.asmr.2022.01.012 ligament (UCL) injury, valgus extension overload, and medial and lateral epicondylitis.

\section{Diagnosis and Treatment of Common Elbow Pathologies}

\section{UCL Injury}

\section{Anatomy and biomechanics}

Soft tissue structures of the elbow provide primary valgus restraint between $20^{\circ}$ and $120^{\circ}$ flexion, the functional motion during overhead throwing. ${ }^{3}$ The UCL is the primary medial restraint and consists of 3 ligaments: anterior oblique, posterior oblique, and transverse. The anterior oblique ligament takes the greatest load during the throwing motion., ${ }^{3,4}$ During throwing, supraphysiological near-tensile failure valgus loads are placed across the elbow joint, with angular velocities at the elbow of up to $3000^{\circ} / \mathrm{sec}^{5}$ This causes large tensile forces across the medial compartment, compressive forces across the lateral compartment, and shear forces posteriorly, a constellation of forces termed "valgus extension overload," which will be discussed in detail subsequently.

\section{Diagnosis}

Accurate diagnosis of UCL injury begins with a thorough history and physical examination. Classically, there is chronic or acute on chronic medial elbow pain during the late cocking/early acceleration phase of throwing, possibly without a distinct injury event. Diagnosis is oftentimes delayed, with neurological symptoms present in as many as $23 \%$ of patients. ${ }^{6}$ Although baseball pitchers make up the majority of 

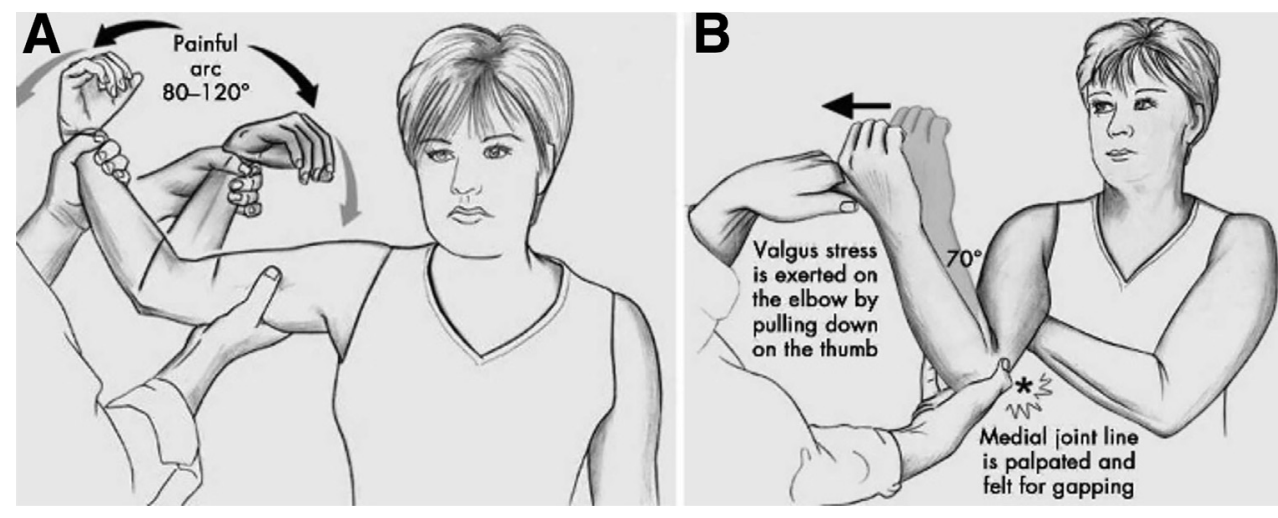

Fig 1. Physical examination of the ulnar collateral ligament (UCL). (A) The moving valgus stress test. With the shoulder abducted and externally rotated, a valgus stress is placed, and the elbow is taken through an arc of flexion from $80^{\circ}$ to $120^{\circ}$. (B) The modified milking maneuver. With the shoulder externally rotated and slightly forward flexed, the elbow is flexed to $70^{\circ}$, and a valgus stress is applied by pulling on the patient's thumb with one hand, while the other hand palpates the UCL (Reprinted with permission from Eygendaal and Safran, Br J Sports Med 2006 May;40(5):430-434). It is important to note pain, amount of valgus opening, and the quality of the endpoint. ${ }^{4}$ However, pain during provocative maneuver should constitute a positive test result, because even with a complete tear, laxity may not be appreciated on examination. ${ }^{8}$

patients, UCL injury is also seen in baseball position players and other overhead/throwing athletes, as well as wrestlers, football players, and soccer players, with the latter groups more likely to have an acute traumatic mechanism. In addition to standard elbow examination, evaluation of the UCL includes palpation from the medial epicondyle to the sublime tubercle, and provocative testing (Fig 1). Imaging can aid diagnosis, with magnetic resonance arthrography reported to have up to $100 \%$ specificity, ${ }^{7}$ and can also detect chondral pathology and loose bodies.

\section{Treatment}

Initial treatment for UCL injuries is generally nonoperative for 3 months, with more expeditious surgical treatment in elite or professional throwers with season-specific demands. General indications for operative management are complete UCL tear or partial tear that is unresponsive to nonoperative management. Nonoperative management consists of rest and rehabilitation with a progressive interval throwing program. With increasing interest in biologics, use of platelet-rich plasma (PRP) injection for UCL injury has grown. Surgically, the gold standard is UCL reconstruction with palmaris autograft (Fig 2). Recently, there has been interest in primary UCL repair, with synthetic weaved suture-like material for ligament augmentation. ${ }^{8}$

Nonoperative treatment of UCL injuries has been reported to have a $42 \%$ rate of return to play (RTP). ${ }^{9}$ With the addition of PRP injection, RTP at same level can improve to $88 \%$ after 12 weeks. However, the data are controversial because other studies of partial UCL tears treated with PRP report $67 \%$ RTP in professional pitchers, with only $36 \%$ of college and $17 \%$ of high school players achieving excellent outcomes. ${ }^{10}$ Surgical reconstruction remains the standard, with numerous large studies demonstrating more than $80 \%$ RTP, with a greater than $90 \%$ satisfaction rate. ${ }^{6}$ Recently, primary UCL repair with synthetic ligament augmentation has been shown allow for a quicker RTP and an $87 \%$ RTP rate. ${ }^{11}$ However, there have not yet been any large comparative studies. In general, it is thought that RTP after nonoperative treatment can occur at 3 to 4 months, whereas after surgical treatment, return is typically at 12 to 18 months, ${ }^{12}$ with primary repair with augmentation techniques possibly allowing return at just over 6 months. ${ }^{11}$

\section{Valgus Extension Overload and Posteromedial Impingement}

\section{Anatomy and Biomechanics}

Posterior impingement is an overuse condition that results from repetitive valgus extension overload (VEO). The combination of valgus and hyperextension, as well as supination, causes shear forces posteriorly between the posteromedial olecranon and the humerus at the olecranon fossa. ${ }^{4}$ Subsequently, resultant soft tissue swelling, loose body formation, osteophyte formation, and physical abutment contribute to posterior elbow pain, crepitus, effusion, locking, and loss of terminal motion. VEO is typically, but not always, accompanied by UCL injury, as increased medial laxity leads to increased excursion with valgus and thus greater load transmission to the posterior-medial olecranon fossa during extension loading. ${ }^{4}$

\section{Diagnosis}

History and examination findings in VEO consist of posteromedial pain during late acceleration and followthrough, ${ }^{13}$ effusion, and mechanical symptoms such as 

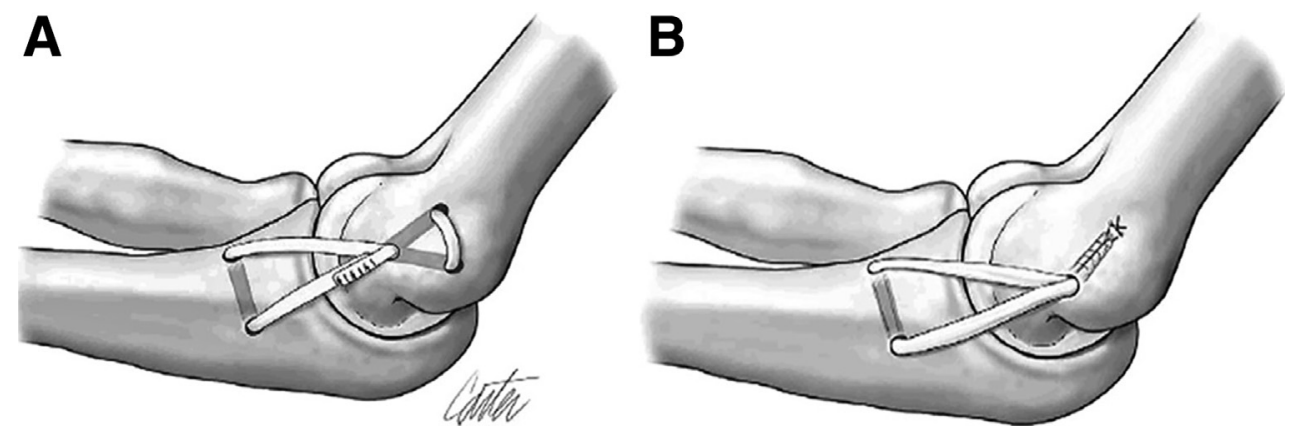

Fig 2. Common techniques for ulnar collateral ligament (UCL) reconstruction with autograft. (A) The Jobe technique in which the palmaris autograft is threaded through tunnels in the ulna and humerus in a figure-of- 8 fashion. (B) The docking technique as developed by Altchek, which uses a blind socket in the humerus. Reproduced with permission from Shah RP, Lindsey DP, Sungar GW, et al. An analysis of four ulnar collateral ligament reconstruction procedures with cyclic valgus loading. $J$ Shoulder Elbow Surg 2009;18(1):60.

loss of terminal extension and catching or locking when loose bodies develop. UCL laxity may also be appreciated. On radiographic examination, medial traction spurs and posteromedial hypertrophic osteophytes can be seen on the ulna, most clearly on axial olecranon view. ${ }^{14}$ Magnetic resonance imaging can further elucidate chondral injury, loose bodies, and UCL integrity.

\section{Treatment}

Treatment consists of nonoperative modalities initially, with rest, ice, and nonsteroidal antiinflammatory drugs to decrease acute pain and inflammation, followed by functional rehabilitation with stretching and strengthening of the elbow and forearm. ${ }^{14}$ Specific emphasis is placed on strengthening the forearm pronators and wrist flexors because of their close association with the UCL and ability to provide dynamic stabilization of the medial elbow. ${ }^{15}$ Surgical intervention is indicated for patients who have failed nonoperative treatment or who have loose bodies or valgus instability caused by UCL incompetence. Arthroscopic decompression is the surgical procedure of choice, because it also facilitates loose body removal and direct evaluation of articular surfaces and the undersurface of the UCL. Elbow arthroscopy has been shown to have good results with $85 \%$ RTP at the same level in both professional and adolescent baseball players, with a $1.6 \%$ complication rate, provided the UCL is intact. ${ }^{16,17}$ If there is valgus instability, UCL reconstruction should be performed to address the root cause. ${ }^{18}$ Care must be taken to avoid over-resection, because resection of native olecranon bone can lead to iatrogenic medial instability. ${ }^{19,20}$

\section{Medial and Lateral Epicondylitis}

\section{Anatomy and Pathophysiology}

The medial and lateral humeral epicondyles serve as origins for numerous tendons that traverse the elbow and wrist joints (Table 1). The mechanism is overuse and repetitive microtrauma; with repetitive wrist flexion and pronation predisposing to medial epicondylitis, and repetitive wrist extension and supination predisposing to lateral epicondylitis. Pathologically, the lesion seen in epicondylitis has been described as angiofibroblastic hyperplasia, ${ }^{21}$ with mucoid degeneration, neovascularization, and fibroblast proliferation. ${ }^{22}$

\section{Diagnosis}

Lateral epicondylitis is more common than medial epicondylitis in the general population and occurs in $1 \%$ to $3 \%$ of adults, ${ }^{23}$ with up to $50 \%$ of recreational tennis players developing the condition at some point in their careers. ${ }^{21}$ Professional tennis players, however, have a greater prevalence of medial epicondylitis. ${ }^{24}$ Typical symptoms include pain centered at the epicondyle, possibly with radiation to the proximal forearm. This may be accompanied by weakness in grip strength and often affects activities of daily living. Although a thorough examination including cervical spine and complete upper extremity evaluation should be performed, classic findings are listed in Table 1 . Imaging may aid diagnosis: although radiographs are typically unremarkable, magnetic resonance imaging has $90 \%$ to $100 \%$ sensitivity and $83 \%$ to $100 \%$ specificity for detecting epicondylitis ${ }^{25}$ and can help delineate the morphology of the tendon origin, the extent of partial tearing, or size of defect if present.

\section{Treatment}

Most patients are successfully treated with conservative measures, and many individuals with epicondylitis may not even seek orthopaedic consultation. ${ }^{26}$ Firstline treatment consists of over-the-counter medication and rest from inciting activity, with counterforce bracing or wrist bracing, with both bracing strategies shown to improve symptoms. ${ }^{27}$ When initial pain 
Table 1. Anatomy and Examination of Medial and Lateral Epicondylitis

\begin{tabular}{lcc}
\hline Diagnosis & Anatomy & Exam \\
\hline $\begin{array}{l}\text { Medial epicondylitis } \\
\text { "Golfer's elbow" }\end{array}$ & Flexor-pronator origin at medial epicondyle & Point tenderness at medial epicondyle \\
Lateral epicondylitis & Pronator Teres \& Flexor carpi radialis most commonly implicated & Painful resisted wrist dorsiflexion \\
"Tennis elbow" & Common extensor origin at lateral epicondyle & Point tenderness at lateral epicondyle \\
Extensor carpi radialis brevis most commonly implicated & Painful resisted wrist palmar flexion \\
\hline
\end{tabular}

subsides, physical therapy may be beneficial, with massage, stretching, and strengthening of the involved muscle/tendon groups with eccentric exercises. One recent eccentric exercise study was published by Tyler et al. ${ }^{28}$ using an elastic-based flexible bar (Thera-Band Flexbar; Hygenic Corp, Akron, $\mathrm{OH}$ ) to provide an eccentric-based overload to the wrist and forearm musculature in addition to a traditional rehabilitation program. Results of their research, performed initially on patients with lateral humeral epicondylitis using a twisting type exercise to eccentrically load the extensor musculature in an elbow-extended position, showed superior results to traditional rehabilitation exercises alone. In athletes and active individuals, the use of a total arm-strengthening approach in rehabilitation involving proximal strengthening of the rotator cuff and scapular musculature has been advocated to optimize kinetic chain function of the upper extremity. ${ }^{29}$ This includes extensive application of exercise progressions to improve scapular stabilization, posterior rotator cuff strength and even core stability exercises. ${ }^{29,30}$ Additional therapeutic modalities of potential benefit include cryotherapy, ultrasonography, iontophoresis, and electrical stimulation.

For more recalcitrant cases, injection therapies can be considered. The utility of corticosteroid in treating epicondylitis is limited, with only short-term benefit because the pathophysiology is predominantly angiofibroblastic hyperplasia rather than a true inflammatory process. $^{31}$ However, most clinicians use steroid injections as an adjunct to rehabilitation, the mainstay of treatment. Recently there has been growing interest in injection of autologous blood products such as PRP, and various stem cell-based injections such as bone marrow aspirate concentrate, direct tenocyte injection, and adipose-derived stem cells. ${ }^{32}$ Although some studies have shown superiority of PRP over corticosteroid injection in terms of pain relief and function, ${ }^{33}$ the literature still does not definitively favor any one type of injection.

Other treatment measures include cold laser and extracorporeal shock wave treatments. ${ }^{34}$ There has been recent interest in 2 "nonsurgical" but somewhat invasive procedures. The Tenex procedure uses an ultrasonic needle that oscillates at high frequency, emulsifying degenerative scar tissue/damaged tendon tissue, and is performed under ultrasound guidance. ${ }^{35}$ The other is the Ten Jet procedure where a special needle is placed under ultrasound guidance, at the area of tendon degeneration, and delivers a pressurized high-velocity stream of saline (salt water) that selectively removes the scar tissue of epicondylitis while sparing the normal tendon. ${ }^{36}$ Both of these newer techniques show promise but await high-quality clinical outcomes studies.

Surgical treatment is ultimately required in $4 \%$ to $11 \%$ of patients with persistent symptoms despite conservative measures. ${ }^{21}$ Operative treatment typically consists of debridement and repair of the affected tendon origin. Medially, open surgery is the mainstay of treatment, because the proximity to the ulnar nerve increases the risk of arthroscopic access. Laterally, arthroscopic and open techniques have been described without significant difference in outcomes. ${ }^{37}$ Surgical treatment has been shown to produce reliably good outcomes, maintained long term, in more than $80 \%$ of patients. $^{38,39}$

\section{Rehabilitation and the Return to Sport Phase}

Of the phases in elbow rehabilitation, the return-tosport (RTS) phase is the one that is most frequently ignored or cut short, resulting in serious potential for reinjury and the development of a "chronic" status of the injury. As with other RTS recommendations, ${ }^{40}$ heavy reliance on objective testing and evidencebased rehab progressions are key elements to apply to determine whether and when an overhead athlete can transition to an interval sport return program. Objective criterion for entry into the RTS stage are first and foremost the tolerance of resistive exercise progressions that include the use of both isolated muscle activation of key stabilizing muscles (posterior rotator cuff, flexor pronator group, and scapular stabilizers), as well as tolerance of functional simulation exercise/movement patterns indicating readiness to initiate actual sportspecific movements in the interval sport return program. Additionally, objectively documented strength equal to the contralateral extremity with either manual muscle testing or, preferably, isokinetic testing or distal grip strength measured with a dynamometer, and functional ROM are essential requirements that are recommended for inclusion in the evaluation for RTS. ${ }^{30}$ It is important to note that often in the elite throwing athlete, chronic musculoskeletal adaptations exist that 
prevent attainment of full elbow extension ROM. This may alter objective goal setting and clinical achievement because full elbow extension ROM may not be attainable equal to the contralateral side. ${ }^{41,42}$ Dines et al. ${ }^{43}$ have also demonstrated the association between proximal dominant arm glenohumeral joint internal rotation deficit and UCL pathology directing clinicians to evaluate not only local elbow range of motion patterning but also proximal shoulder rotation range of motion in the complete rehabilitation and return to functional activity of athletic patients with elbow pathology.

Additional parameters included in the pre-return to activity evaluation of the throwing athlete include provocation maneuvers that simulate elbow loading encountered during the throwing or serving motion. These include orthopaedic manual examination techniques such as the subluxation/relocation test, O'Driscoll's moving valgus test and standard valgus stress tests in addition to the valgus extension overpressure test. ${ }^{44}$ Finally, unlike the lower extremity where many standardized functional tests are reported with population specific normative data, few if any functional tests are reported for the elbow. The use of the closed kinetic chain stability test ${ }^{45}$ and upper extremity $\mathrm{Y}$ balance test $^{46,47}$ have both been applied in upper extremity athletes and can be used in combination with upper extremity plyometric progressions ${ }^{48}$ with light loads progressing toward functional speeds to represent readiness for the RTS-specific activity. ${ }^{29,30,44}$ Athletes undergoing elbow rehabilitation who do not meet these important criterion are delayed in the transition to the interval program.

Characteristics of interval sport return programs include alternate day performance, as well as gradual progressions of intensity and repetitions of sport activities. For example, using low-compression tennis balls during the initial contact phase of the return to tennis decreases impact stress and increases tolerance to the activity. Performing the interval program under supervision, either during therapy or with a knowledgeable teaching professional or coach, allows for the biomechanical evaluation of technique and guards against overzealous intensity levels, which can be a common mistake in well-intentioned, motivated athletic patients. Using the return program on alternate days, with rest between sessions, allows for recovery and decreases the potential for reinjury.

Two other important aspects of the RTS activity are the continued application of resistive exercise and the modification or evaluation of the patient's equipment. Continuation of the total-arm strength rehabilitation exercises using elastic resistance, medicine balls, and isotonic or isokinetic resistance is important to continue to enhance not only strength but also muscular endurance. Inspection and modification of the patient's tennis racquet or golf clubs is also important. For example, lowering the string tension several pounds and ensuring that the player uses a more resilient or softer string, such as a coreless multifilament synthetic string or gut, is widely recommended for tennis players with upperextremity injury histories. ${ }^{29,30}$ Grip size is also very important with research showing changes in muscular activity with alteration of handle or grip size. ${ }^{29}$ Measurement of proper grip size has been described by Ellenbecker et al. ${ }^{29}$ as corresponding to the distance between the distal tip of the ring finger along the radial border of the finger to the proximal palmar crease. Ellenbecker et al. ${ }^{29}$ also recommend the use of a counterforce brace to decrease stress on the insertion of the flexor and extensor tendons during work or sport activity during the recovery from humeral epicondylitis.

The use of specifically interval throwing programs for baseball and softball athletes are comprised of progressive distance and repetition based formats to gradually stress the recovering upper extremity following elbow injury. Several widely published protocols are available based on knowledge of the sport and position specific demands of the athlete undergoing rehabilitation. ${ }^{30,49,50}$ Similar to characteristics of interval tennis programs, emphasis on proper throwing technique and attention to details beyond the upper extremity are useful and important based on recent research on the role of the crow-hop and elbow loading. ${ }^{51}$ Additionally, Fleisig and colleagues $^{52}$ have objectively studied and outlined the extremity loading characteristics of "long" toss throwing as compared to other specific throwing variations. Their fine study enables the clinician to guide the throwing athlete appropriately through the interval throwing progressive stages based on position (outfielder vs middle infielder vs pitcher) to ensure optimal and safe demands are imposed on the rehabilitating athlete.

\section{Summary}

In summary, this review provides a framework for approaching the diagnosis, treatment, and particularly rehabilitation, of common elbow pathologies in overhead and throwing athletes, specifically UCL injury, valgus extension overload, and medial and lateral epicondylitis. Advanced rehabilitation facilitates full return to functional sport-specific activity, and is based on objective criteria. As diagnostic and therapeutic modalities improve and guide our understanding of elbow pathologies in the athletic patient, continued research will further provide clinicians with objective evidencebased rehabilitation techniques for both evaluation and treatment of the athlete with elbow injury. 


\section{References}

1. Saper MG, Pierpoint LA, Liu W, Comstock RD, Polousky JD, Andrews JR. Epidemiology of shoulder and elbow injuries among United States high school baseball players: School years 2005-2006 through 2014-2015. Am J Sports Med 2018;46:37-43.

2. Ciccotti MG, Pollack KM, Ciccotti MC, et al. Elbow injuries in professional baseball: Epidemiological findings from the Major League Baseball Injury Surveillance System. Am J Sports Med 2017;45:2319-2328.

3. Cain EL Jr, Dugas JR, Wolf RS, Andrews JR. Elbow injuries in throwing athletes: A current concepts review. Am J Sports Med 2003;31:621-635.

4. Eygendaal D, Safran MR. Postero-medial elbow problems in the adult athlete. Br J Sports Med 2006;40:430-434. ; discussion 444.

5. Fleisig GS, Andrews JR, Dillman CJ, Escamilla RF. Kinetics of baseball pitching with implications about injury mechanisms. Am J Sports Med 1995;23:233-239.

6. Cain EL Jr, Andrews JR, Dugas JR, et al. Outcome of ulnar collateral ligament reconstruction of the elbow in 1281 athletes: Results in 743 athletes with minimum 2-year follow-up. Am J Sports Med 2010;38:2426-2434.

7. Nakanishi K, Masatomi T, Ochi T, et al. MR arthrography of elbow: Evaluation of the ulnar collateral ligament of elbow. Skeletal Radiol 1996;25:629-634.

8. Bruce JR, Andrews JR. Ulnar collateral ligament injuries in the throwing athlete. J Am Acad Orthop Surg 2014;22: 315-325.

9. Rettig AC, Sherrill C, Snead DS, Mendler JC, Mieling P. Nonoperative treatment of ulnar collateral ligament injuries in throwing athletes. Am J Sports Med 2001;29: 15-17.

10. Dines JS, Williams PN, El Attrache N, et al. Platelet-rich plasma can be used to successfully treat elbow ulnar collateral ligament insufficiency in high-level throwers. Am J Orthop (Belle Mead NJ) 2016:45:296-300.

11. Dugas JR, Looze CA, Capogna B, et al. Ulnar collateral ligament repair with collagen-dipped fibertape augmentation in overhead-throwing athletes. Am J Sports Med 2019;47:1096-1102.

12. Carr JB 2nd, Camp CL, Dines JS. Elbow ulnar collateral ligament injuries: indications, management, and outcomes. Arthroscopy 2020;36:1221-1222.

13. Miller CD, Savoie FH 3rd. Valgus extension injuries of the elbow in the throwing athlete. J Am Acad Orthop Surg 1994;2:261-269.

14. Chen FS, Rokito AS, Jobe FW. Medial elbow problems in the overhead-throwing athlete. J Am Acad Orthop Surg 2001;9:99-113.

15. Davidson PA, Pink M, Perry J, Jobe FW. Functional anatomy of the flexor pronator muscle group in relation to the medial collateral ligament of the elbow. Am J Sports Med 1995;23:245-250.

16. Reddy AS, Kvitne RS, Yocum LA, Elattrache NS, Glousman RE, Jobe FW. Arthroscopy of the elbow: A long-term clinical review. Arthroscopy 2000;16: 588-594.

17. Park JY, Yoo HY, Chung SW, et al. Valgus extension overload syndrome in adolescent baseball players: Clinical characteristics and surgical outcomes. J Shoulder Elbow Surg 2016;25:2048-2056.

18. Andrews JR, Timmerman LA. Outcome of elbow surgery in professional baseball players. Am J Sports Med 1995;23: 407-413.

19. Noticewala MS, Vance DD, Trofa DP, Ahmad CS. Elbow arthroscopy for treatment of valgus extension overload. Arthrosc Tech 2018;7:e705-e710.

20. Goodwin D, Dynin M, Macdonnell JR, Kessler MW. The role of arthroscopy in chronic elbow instability. Arthroscopy 2013;29:2029-2036.

21. Brummel J, Baker CL 3rd, Hopkins R, Baker CL Jr. Epicondylitis: Lateral. Sports Med Arthrosc Rev 2014;22:el-e6.

22. Kraushaar BS, Nirschl RP. Tendinosis of the elbow (tennis elbow). Clinical features and findings of histological, immunohistochemical, and electron microscopy studies. J Bone Joint Surg Am 1999;81:259-278.

23. Jobe FW, Ciccotti MG. Lateral and medial epicondylitis of the elbow. J Am Acad Orthop Surg 1994;2:1-8.

24. Eygendaal D, Rahussen FTG, Diercks RL. Biomechanics of the elbow joint in tennis players and relation to pathology. Br J Sports Med 2007;41:820-823.

25. Miller TT, Shapiro MA, Schultz E, Kalish PE. Comparison of sonography and MRI for diagnosing epicondylitis. J Clin Ultrasound 2002;30:193-202.

26. Carroll R. Tennis elbow: Incidence in local league players. Br J Sports Med 1981;15:250-256.

27. Garg R, Adamson GJ, Dawson PA, Shankwiler JA, Pink MM. A prospective randomized study comparing a forearm strap brace versus a wrist splint for the treatment of lateral epicondylitis. J Shoulder Elbow Surg 2010;19: 508-512.

28. Tyler TF, Thomas GC, Nicholas SJ, McHugh MP. Addition of isolated wrist extensor eccentric exercise to standard treatment for chronic lateral epicondylosis: A prospective randomized trial. J Shoulder Elbow Surg 2010;19:917-922.

29. Ellenbecker TS, Nirschl R, Renstrom P. Current concepts in examination and treatment of elbow tendon injury. Sports Health 2013;5:186-194.

30. Ellenbecker TS, Wilk KE. Sport therapy for the shoulder: Evaluation, rehabilitation e return to spoort. Champagne, IL: Human Kinetics Publishing, 2017.

31. Gulabi D, Uysal MA, Akça A, Colak I, Çeçen GS, Gumustas S. USG-guided injection of corticosteroid for lateral epicondylitis does not improve clinical outcomes: A prospective randomised study. Arch Orthop Trauma Surg 2017; 137:601-606.

32. Tarpada SP, Morris MT, Lian J, Rashidi S. Current advances in the treatment of medial and lateral epicondylitis. J Orthop 2018;15:107-110.

33. Halpern BC, Chaudhury S, Rodeo SA. The role of plateletrich plasma in inducing musculoskeletal tissue healing. HSS J 2012;8:137-145.

34. Testa G, Vescio A, Perez S, et al. Extracorporeal shockwave therapy treatment in upper limb diseases: A systematic review. J Clin Med 2020;9:453.

35. Altahawi F, Li X, Demarest B, Forney MC. Percutaneous ultrasonic tenotomy with the TX-1 device versus surgical tenotomy for the treatment of common extensor tendinosis. Skeletal Radiol 2021;50:115-124. 
36. Wong AK, Swami PN, Reed TF, Bitterman A, Grande DA. Efficacy and safety of a percutaneous tenotomy system for debridement of tendinopathic tissues. J Long Term Eff Med Implants 2018;28:199-203.

37. Szabo SJ, Savoie FH 3rd, Field LD, Ramsey JR, Hosemann CD. Tendinosis of the extensor carpi radialis brevis: An evaluation of three methods of operative treatment. J Shoulder Elbow Surg 2006;15:721-727.

38. Baker CL Jr, Baker CL 3rd. Long-term follow-up of arthroscopic treatment of lateral epicondylitis. Am J Sports Med 2008;36:254-260.

39. Amin NH, Kumar NS, Schickendantz MS. Medial epicondylitis: Evaluation and management. J Am Acad Orthop Surg 2015:23:348-355.

40. Ardern CL, Glasgow P, Schneiders A, et al. 2016 Consensus statement on return to sport from the First World Congress in Sports Physical Therapy, Bern. Br J Sports Med 2016;50:853-864.

41. Wright RW, Steger-May K, Wasserlauf BL, O'Neal ME, Weinberg BW, Paletta GA. Elbow range of motion in professional baseball pitchers. Am J Sports Med 2006;34: 190- 193.

42. Ellenbecker TS, Mattalino AJ, Elam EA, Caplinger RA. Medial elbow joint laxity in professional baseball pitchers. A bilateral comparison using stress radiography. Am J Sports Med 1998;26:420-424.

43. Dines JS, Frank JB, Akerman M, Yocum LA. Glenohumeral internal rotation deficits in baseball players with ulnar collateral ligament insufficiency. Am J Sports Med 2009;37:566-570.
44. Ellenbecker TS, Wilk KE, Altchek DW, Andrews JR. Current concepts in rehabilitation following ulnar collateral ligament reconstruction. Sports Health 2009;1:301-313.

45. Goldbeck TG, Davies GJ. Test-retest reliability of the closed kinetic chain upper extremity stability test: A clinical field test. J Sport Rehabil 2000;9:35-45.

46. Borms D, Cools A. Upper-extremity functional performance tests: reference values for overhead athletes. Int $J$ Sports Med 2018;39:433-441.

47. Tarara DT, Fogaca LK, Taylor JB, Hegedus EJ. Clinicianfriendly physical performance tests in athletes part 3: A systematic review of measurement properties and correlations to injury for tests in the upper extremity. $\mathrm{Br} J$ Sports Med 2016;50:545-551.

48. Ellenbecker TS, Sueyoshi T, Bailie DS. Muscular activation during plyometric exercises in $90^{\circ}$ of glenohumeral joint abduction. Sports Health 2015;7:75-79.

49. Reinold MM, Wilk KE, Reed J, Crenshaw K, Andrews JR. Interval sport programs: Guidelines for baseball, tennis, and golf. J Orthop Sports Phys Ther 2002;32:293-298.

50. Axe M, Hurd W, Snyder-Mackler L. Data-based interval throwing programs for baseball players. Sports Health 2009;1:145-153.

51. Lizzio VA, Smith DG, Guo EW, et al. The effect of the crow hop on elbow stress during an interval throwing program. Am J Sports Med 2021;49:359-363.

52. Fleisig GS, Bolt B, Fortenbaugh D, Wilk KE, Andrews JR. Biomechanical comparison of baseball pitching and longtoss: Implications for training and rehabilitation. J Orthop Sports Phys Ther 2011;41:296-303. 